\title{
A study of high-speed slurry erosion of NiCrBSi thermal-sprayed coating
}

\author{
M.C. Lin ${ }^{\text {a }}$, L.S. Chang ${ }^{\text {a }}$, H.C. Lin ${ }^{\text {b,* }}$, C.H. Yang ${ }^{c}$, K.M. Lin ${ }^{c}$ \\ ${ }^{a}$ Department of Materials Engineering, National ChungHsing University, Taichung, Taiwan \\ ${ }^{\mathrm{b}}$ Department of Materials Science and Engineering, National Taiwan University, Taipei, Taiwan \\ ${ }^{\mathrm{c}}$ Department of Materials Science and Engineering, Feng Chia University, Taichung, Taiwan
}

Received 21 April 2006; accepted in revised form 27 June 2006

Available online 2 August 2006

\begin{abstract}
The test specimens of NiCrBSi coating were prepared using the high velocity oxy-fuel spraying technique with a post-thermal treatment. Their high-speed slurry erosion characteristics have been systematically studied. SUS304 stainless steel was selected as the comparison material. Experimental results show that the NiCrBSi sprayed coating exhibits a much better slurry erosion resistance than the SUS304 stainless steel. The erosion rate for the $\mathrm{NiCrBSi}$ sprayed coating slightly increases with the impinged angle. However, a maximum erosion rate appears at an impinged angle of around $30^{\circ}$ for SUS304 stainless steel. Both NiCrBSi sprayed coating and SUS304 stainless steel exhibit impinged surfaces with lots of furrows at an impinged angle of $30^{\circ}$. At a high impinged angle of $90^{\circ}$, the SUS304 stainless steel exhibits an impinged surface with lots of overlapping and irregular concavities, while, these features are less obvious for NiCrBSi sprayed coating. The hardness of SUS304 stainless steel increases significantly with increasing impinged angle during the high-speed slurry erosion. But, there is no obvious work hardening for the NiCrBSi sprayed coating due to its extra-high hardness and less plastic deformation, even at a high impinged angle of $90^{\circ}$.
\end{abstract}

(C) 2006 Elsevier B.V. All rights reserved.

Keywords: NiCrBSi coating; High velocity oxy-fuel spraying; High-speed slurry erosion

\section{Introduction}

The turbine blades, needles and nozzles in the hydraulic machinery have to tolerate perpetual high-speed water (with or without solid particles) impingement, and hence they must have excellent strength, toughness and erosion resistance. However, the erosion resistance of conventional turbine blades, made of lowcarbon steel, low-manganese steel, stainless steel, white cast iron or plastic resin, is very low. These turbine blades are easily damaged under high-speed water (with or without solid particles) impingement, thus interrupting hydraulic power generation [1,2]. Hence, it is important to develop more erosion-resistant materials.

Recently, various hardfacing coatings with different compositions have been developed and mainly used in the chemical industry, petrol industry, and for valves, hot working punches, mud purging elements in cement factories. Among these hardfacing

\footnotetext{
* Corresponding author. Tel.: +88623366 4532; fax: +886223634562.
}

E-mail address: hclinntu@ntu.edu.tw (H.C. Lin). coatings, the nickel-based self-fluxing alloys (NiCrBSi-based alloys) [3-11] are more attractive due to their excellent wear and corrosion resistance at high temperatures and their relatively low cost. The alloying elements of boron, chromium and carbon in these alloys will produce the hard phases of borides, carbides and hence raise the cavitation and wear resistance of the coatings. The direct addition of various hard compounds, such as WC, TiC and $\mathrm{B}_{13} \mathrm{C}_{2}$, can also significantly improve the tribological properties of these coatings. Tu et al. [12] reported that the WC addition can improve the erosion resistance at high temperatures of $400-500^{\circ} \mathrm{C}$. Sugiyama et al. [13] also studied the slurry wear of $\mathrm{WC} / \mathrm{Ni} / \mathrm{Cr} / \mathrm{Co}$ spray-fused coating at flow speeds of $10-40 \mathrm{~m} / \mathrm{s}$ and found that the coating hardness had an important influence on the slurry wear resistance of the sprayed coatings. In the hydraulic power generation, however, the hydraulic machinery often encounters the slurry attack with a flow speed even higher than $100 \mathrm{~m} / \mathrm{s}$. Our understanding in this area of high-speed slurry attack for these sprayed coatings is incomplete. In the present study, hence, we aim to investigate the slurry erosion characteristics of $\mathrm{NiCrBSi}$ thermalsprayed coating by using the high-speed water/sand impingement 
Table 1

Parameters of high velocity oxy-fuel spraying used in the present study

\section{Gun type}

Substrate preheat $\left({ }^{\circ} \mathrm{C}\right)$

Powder feed rate $\left(\mathrm{lb} \mathrm{h}^{-1}\right)$

Spray distance (mm)

Flow rate of $\mathrm{C}_{2} \mathrm{H}_{2}\left(1 \mathrm{~min}^{-1}\right)$

Flow rate of $\mathrm{O}_{2}\left(1 \mathrm{~min}^{-1}\right)$

Air pressure (lb in. ${ }^{-2}$ )
Table 2

Parameters of water/sand impingement erosion used in the present study

\begin{tabular}{ll}
\hline Impinged angle $\left({ }^{\circ}\right)$ & $15,30,45,60,75,90$ \\
Impinged speed $(\mathrm{m} / \mathrm{s})$ & $82.9,90.8,99.5,105,117.3$ \\
Impinged medium & Fresh water mixed with fresh quartz sand \\
Sand flow $(\mathrm{g} / \mathrm{min})$ & $2 \pm 0.5$ \\
Sand size $(\mu \mathrm{m})$ & $263-363$ \\
Erosion time $(\mathrm{h})$ & 2 \\
Test temperature $\left({ }^{\circ} \mathrm{C}\right)$ & 25 \\
\hline
\end{tabular}

angle difference between the impinged trace and the notch was $\theta$. The speed of the impinged flow $(V)$ could be calculated from Eq. (1).

$$
V=L \omega / \theta
$$

The surface morphologies were observed by a Topcon ABT-55 SEM. Porosity of the sprayed coating was measured from the micrographs with the aid of an image analyzer. The hardness of the as-impinged surface was carefully measured with a micro-Vickers tester using a load of $300 \mathrm{~g}$ for $15 \mathrm{~s}$. For each specimen, the average hardness value was calculated from at least five test readings. The weight loss after impingement erosion was measured by using a precise electronic balance, with a weighing accuracy of $\pm 0.01 \mathrm{mg}$.

\section{Results and discussion}

\subsection{Factors influencing the slurry erosion characteristics of NiCrBSi sprayed coating}

There are many factors that influence the slurry erosion rate. The flow conditions along with the properties of target material as well as the fluid and particle influence the impact dynamics of the impinged particle-to-target surface interactions and thus the erosion rate. The general expression for erosion rate, $W$, has been established empirically as below $[19,20]$ :

$W=M_{\mathrm{P}} K f(\alpha) V_{\mathrm{P}}^{n}$

Where $M_{\mathrm{P}}$ is the mass of impinged particles impacting the surface, $V_{\mathrm{P}}$ is the particle velocity on impact and $f(\alpha)$ is a functional rotation speed. The distance between these two disks was $L$ and the

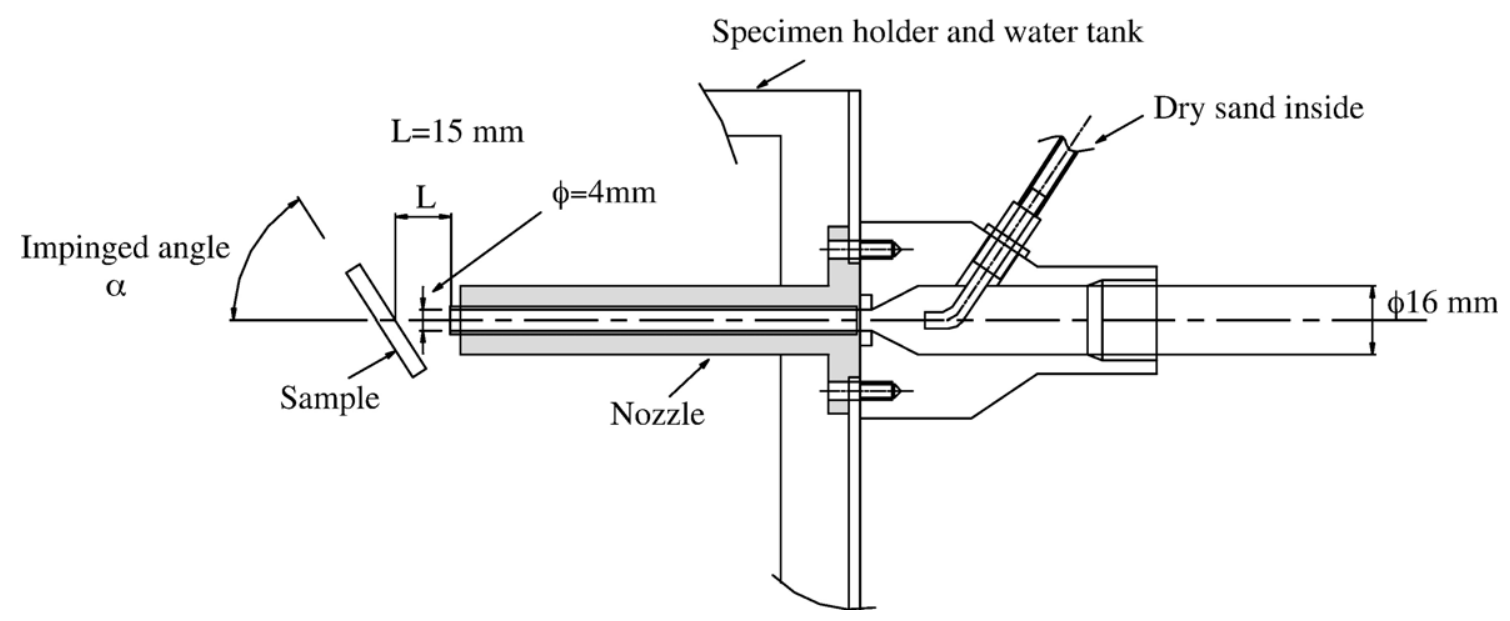

Fig. 1. Configuration of the impingement erosion testing equipment. 


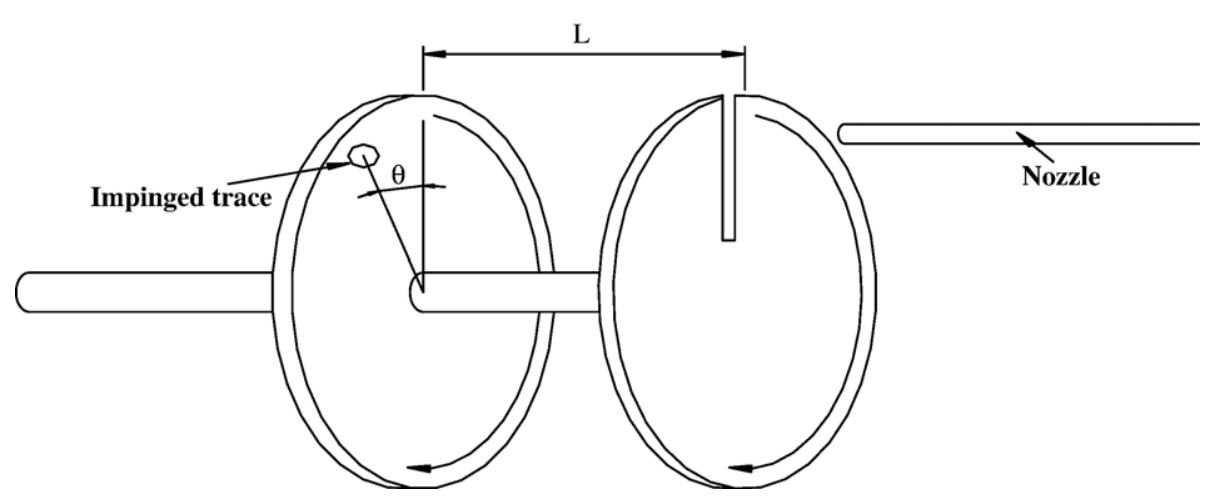

Fig. 2. Illustration of the double disk method used to measure the impinged speed.

relationship for the dependence of the erosion rate on the impact angle. $K$ and $n$ are constants depending on the properties of the target material, such as the hardness, elastic modulus, facture toughness and surface roughness. Besides, the thermal expansion, bond strength, residual stress and thickness of the hardfacing coatings also have important effects on the erosion behaviors.

According to Richardson [21], when the impinged particles are harder than the tested specimen and exceed a critical size, say 120 $130 \mu \mathrm{m}$ for ductile materials and $100-125 \mu \mathrm{m}$ for brittle materials, the intrinsic properties of impinged particles will have no obvious effect on the impingement erosion rate. Meanwhile, impinged particles with irregular shape will cause serious erosion damage [22], which will shed light on the impingement erosion characteristics of the tested materials. Hence, the impinged particles used in this study, 263-363 $\mu \mathrm{m}$ quartz sand with irregular shape, can be considered as a controlled impingement parameter. We mainly investigate the influences of flow speed and impact angle of impinged particles on the slurry erosion characteristics of the HVOF sprayed $\mathrm{NiCrBSi}$ coating in this study.

Fig. 3(a-b) shows the typical surface morphologies of the post-thermal-treated NiCrBSi coating and SUS304 stainless steel, respectively. Shieh et al. [14] had discussed more the microstructures, amount of porosity and existing phases for the as-sprayed and post-thermal-treated NiCrBSi coatings. They had found that the porosity can be significantly reduced from 20 to $0.3 \mathrm{vol} . \%$ by the post-thermal treatment. This feature can also be observed in Fig. 3(a) for the post-thermal-treated NiCrBSi coating. This dense structure of post-thermal-treated NiCrBSi coating is believed to exhibit a better slurry erosion resistance than the as-sprayed coating with higher amount of porosity. Hence, all the NiCrBSi spayed coatings have been carried out with a post-thermal treatment prior to testing in this study. Apart from the metallurgical properties, many testing parameters, e.g., the erosion time, impinged angle and impinged flow speed in this study, can also influence the impingement erosion characteristics of NiCrBSi sprayed coating. During the highspeed impingement of pure water, there is no obvious change for the NiCrBSi sprayed coating even when the erosion time reaches $10 \mathrm{~h}$. This feature also indicates that the NiCrBSi coatings have an excellent resistance of corrosion due to the existence of a large quantity of $\mathrm{Ni}$ and $\mathrm{Cr}$ elements. Hence, after a long period of impingement by pure water, there is even no erosion or corrosion trace. In comparison, the surface mor-
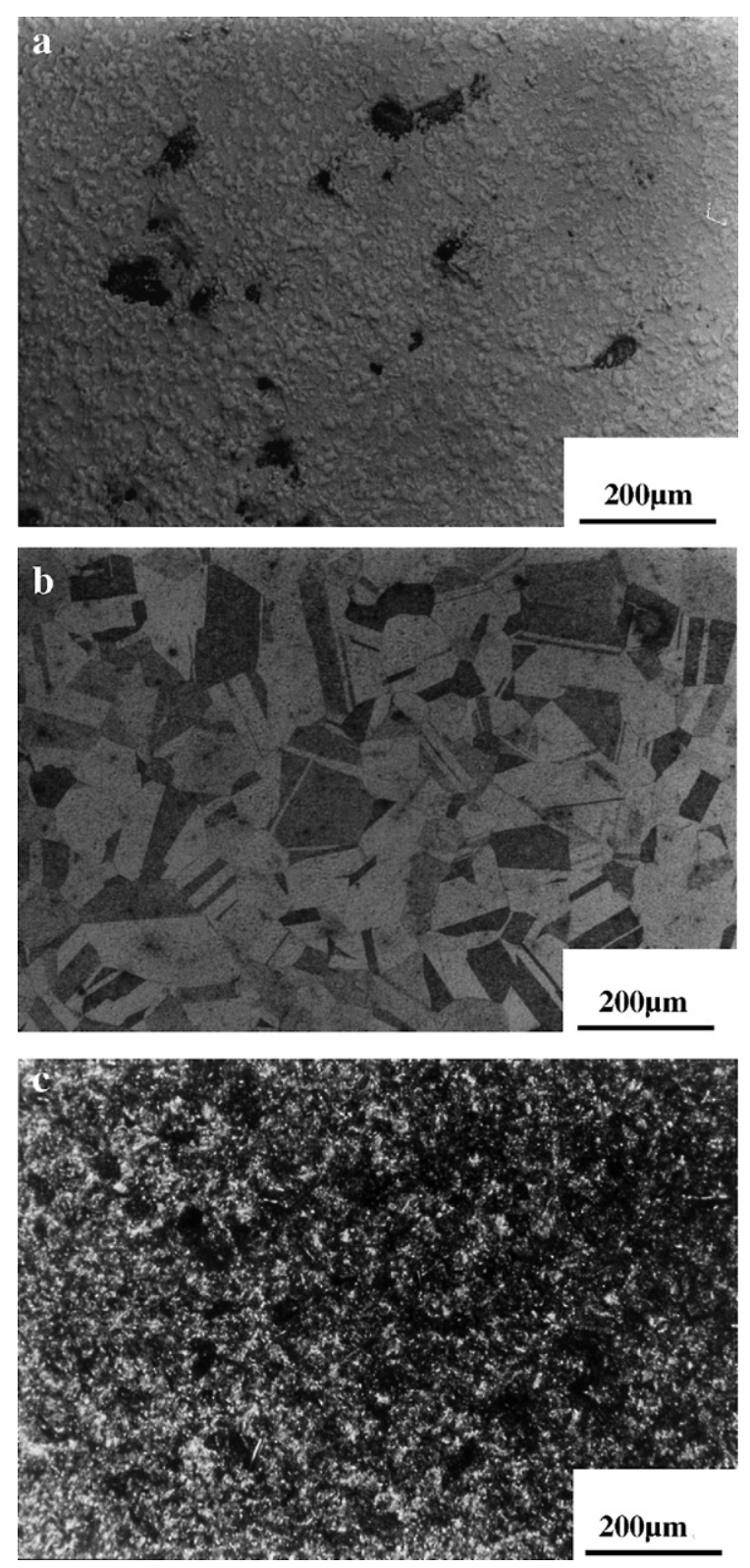

Fig. 3. Optical surface morphologies of (a) NiCrBSi sprayed coating, (b) original SUS304 stainless steel and (c) SUS304 stainless steel subjected to impingement erosion of pure water for $10 \mathrm{~h}$. 

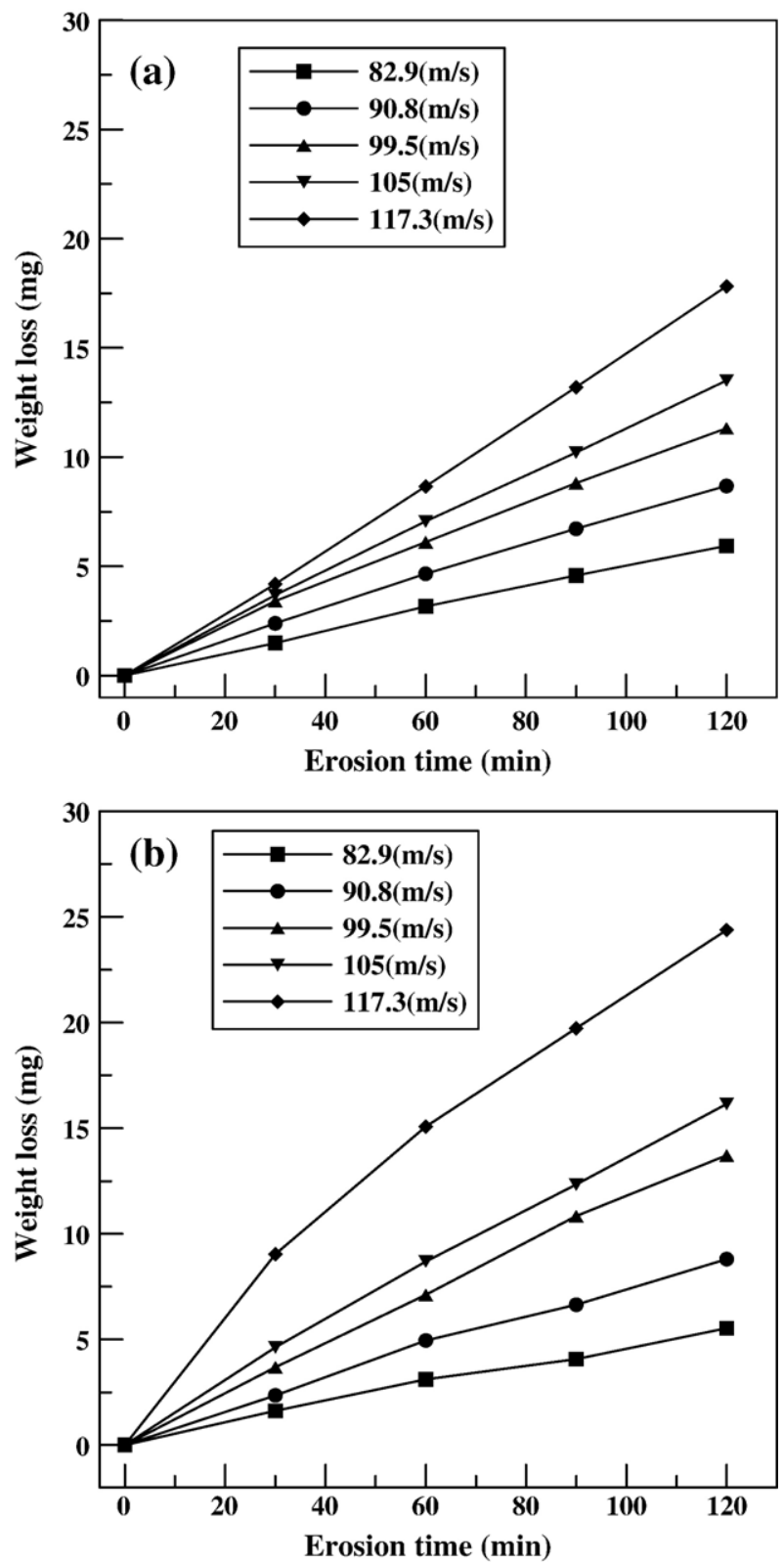

Fig. 4. Cumulative weight losses versus erosion time for NiCrBSi sprayed coating after impingement at (a) $30^{\circ}$ and (b) $90^{\circ}$ angles, and with impinged speeds ranging from 82.9 to $117.3 \mathrm{~m} / \mathrm{s}$.

phology of SUS304 stainless steel has obvious erosion trace after $10 \mathrm{~h}$ impingement, as shown in Fig. 3(c).

\subsubsection{Erosion time}

Fig. 4(a-b) shows the cumulative weight loss versus erosion time at various impinged speeds ranging from 82.9 to $117.3 \mathrm{~m} / \mathrm{s}$ for $\mathrm{NiCrBSi}$ sprayed coating at $30^{\circ}$ and $90^{\circ}$ impinged angles, respectively. The cumulative weight losses versus erosion time at other impinged angles show a similar variation tendency to those in Fig. 4(a-b), and are omitted here. As seen in Fig. 4(a-b), the cumulative weight losses increase linearly with the increasing erosion time. This indicates that the erosion mechanism for the NiCrBSi sprayed coating does not change noticeably, implying a steady erosion damage during the impingement process, regardless of the variation in impinged angle and speed.

\subsubsection{Impinged angle and speed}

Fig. 5(a-b) shows the erosion rate versus impinged angle at various impinged speeds for $\mathrm{NiCrBSi}$ sprayed coating and SUS304 stainless steel, respectively. The gravimetric erosion rate, commonly used to measure the erosion damage [23], is defined as the weight loss from the specimen surface per unit weight of impinged particles. In Fig. 5(a), the erosion rate for the NiCrBSi sprayed coating is found to slightly increase with impinged angles. Hence, the difference of erosion rate at high and low impinged angles is quite small, except that at the impinged speed of $117.3 \mathrm{~m} / \mathrm{s}$. At this super-high impinged speed, an obvious increment of erosion rates with increasing impinged angles can be observed. On the contrary, Fig. 5(b) shows that the maximum erosion rates appear at a $30^{\circ}$ impinged angle for SUS304 stainless steel, especially at higher impinged speeds. These phenomena can be explained below. As reported in previous studies [24-29], the ductile materials exhibit a
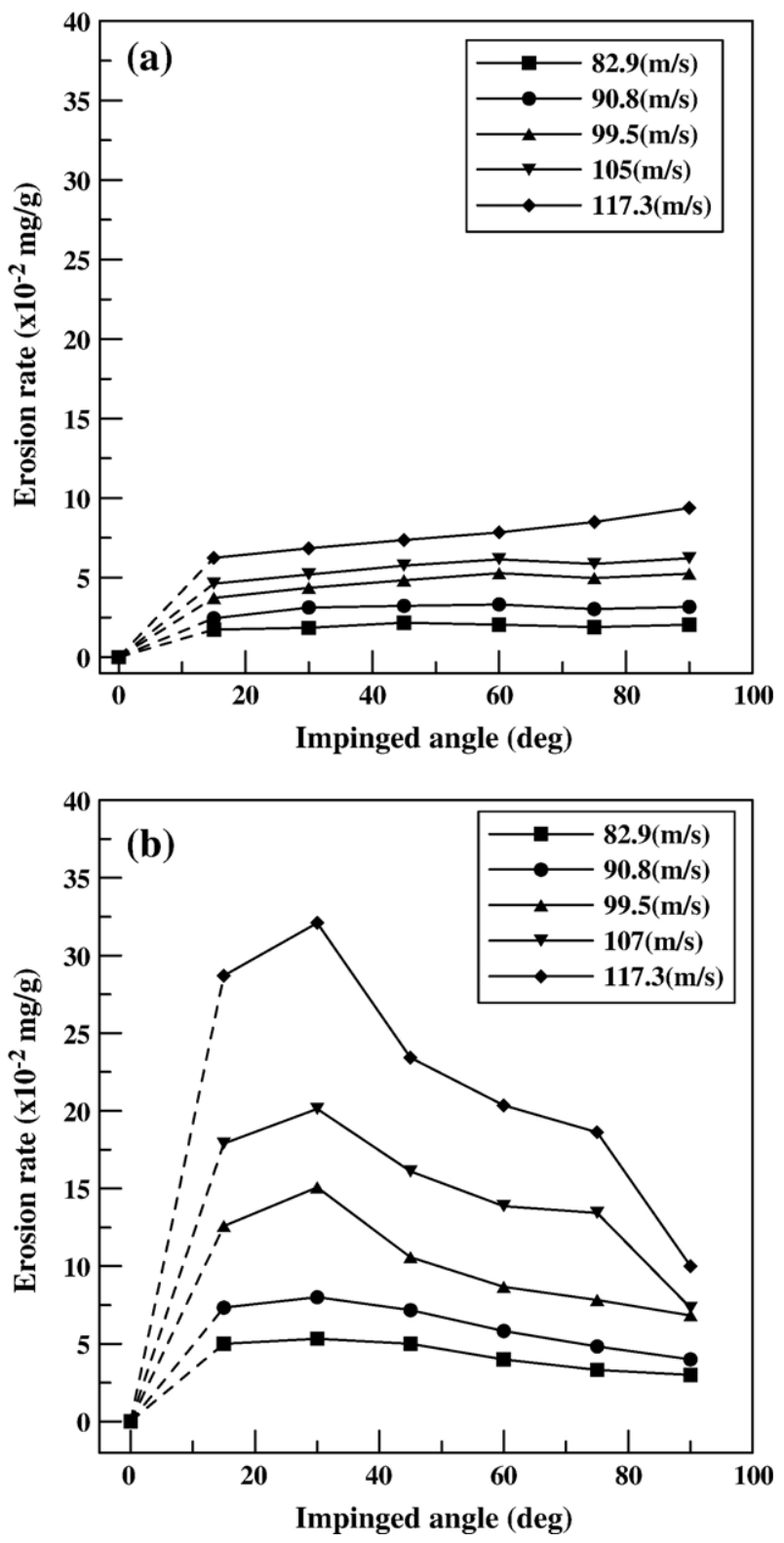

Fig. 5. Erosion rates versus impinged angle for (a) NiCrBSi sprayed coating and (b) SUS304 stainless steel at various impinged speeds. 

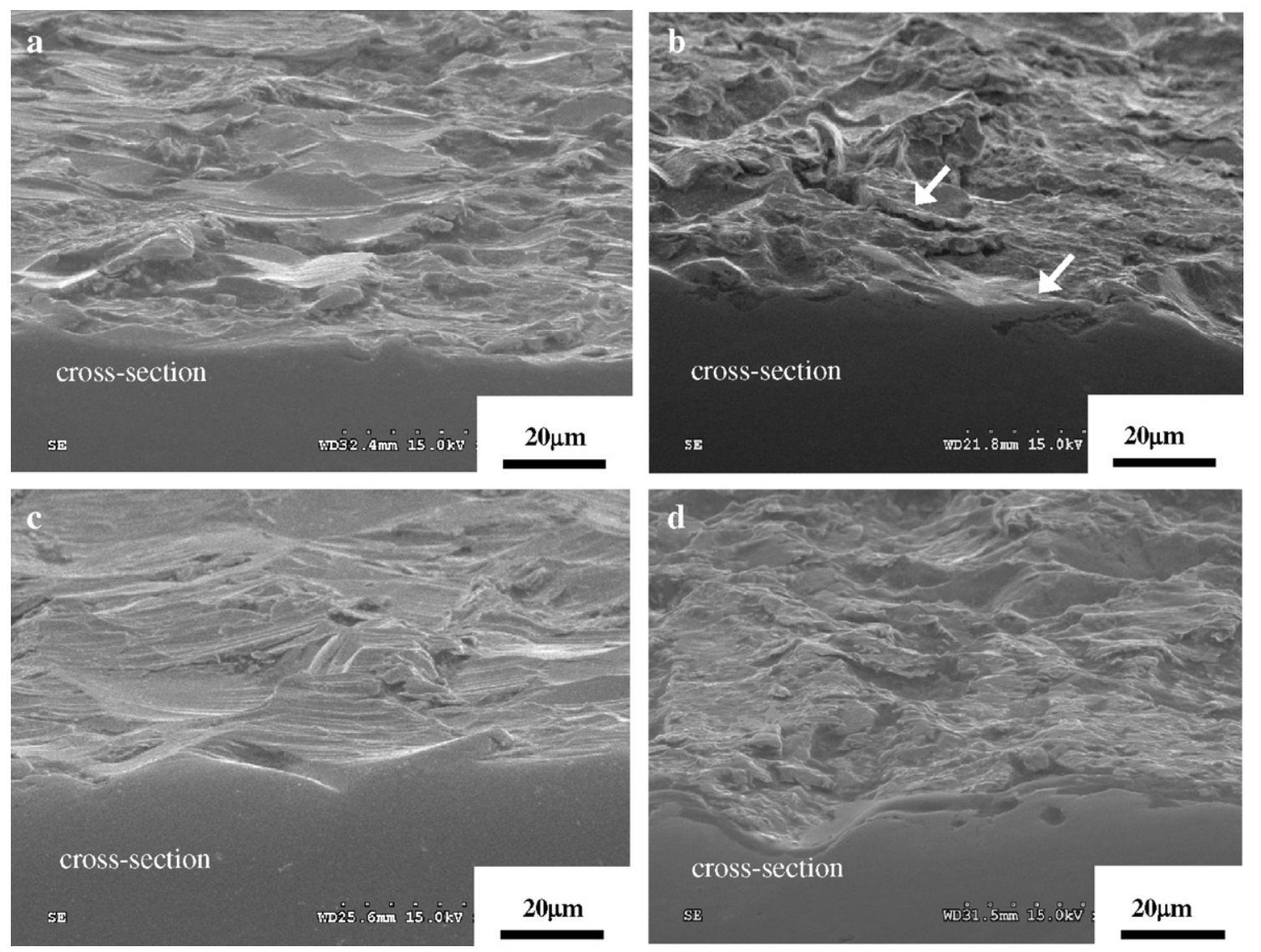

Fig. 6. Scanning electron micrographs of impinged surfaces for (a-b) SUS304 stainless steel and (c-d) NiCrBSi sprayed coating, subjected to an impingement erosion of $2 \mathrm{~h}$ at various angles. (a), (c) $30^{\circ}$; (b), (d) $90^{\circ}$. The specimens are observed with a tilting of $15^{\circ}$ from the cross-section view.

maximum erosion rate at around $30^{\circ}$ impinged angle. The highspeed impingement at low impinged angle will enhance material removal by microcutting, thus increasing the erosion rate. At high impinged angles, the normal compressive force will mainly produce the accumulated damage from fatigue, shear localization, microforging and extrusion processes. These processes could only produce slighter erosion damage than that by cutting removal at low impinged angles. Hence, there appears a maximum erosion rate at about $30^{\circ}$ impinged angle for ductile materials, such as SUS304 stainless steel. However, the material removal by microcutting at low impinged angles for $\mathrm{NiCrBSi}$ coatings is quite slight due to their extra-high hardness (a high toughness is also considered). These NiCrBSi coatings can also have a less plastic deformation at high impinged angles and exhibit a slight erosion rate. Meanwhile, the micro-porosities existing within the $\mathrm{NiCrBSi}$ coatings will also play an important role on their erosion damage. All these features make the NiCrBSi coatings exhibit a different erosion behavior from the SUS304 stainless steel.

As compared in Fig. 5(a-b), the erosion resistance of NiCrBSi sprayed coating is much higher than that of SUS304 stainless steel, especially at lower impinged angles and higher impinged speeds. Namely, NiCrBSi sprayed coating is an excellent erosion-resistant material. In fact, a preliminary test has revealed that the NiCrBSi spray coating can increase significantly the using-life, 3-4 times, of needles and nozzles in hydraulic machinery.

\subsection{Surface morphology and hardness after impingement erosion}

Fig. 6(a-b) and (c-d) shows SEM micrographs of the impinged surfaces for the SUS304 stainless steel and NiCrBSi sprayed coating, respectively, subjected to impingement erosion of $2 \mathrm{~h}$ at an impinged speed of $99.5 \mathrm{~m} / \mathrm{s}$ and impinged angles of $30^{\circ}$ and $90^{\circ}$. To clearly present both the surface morphologies and cross sections, the impinged specimens are observed with a tilting of $15^{\circ}$ from the cross-section view. No cracks are observed in the cross sections of Fig. 6(a-d). This indicates that both SUS304 stainless steel and NiCrBSi sprayed coating exhibit a ductile behavior. Moreover, two distinct surface morphologies can be found in these micrographs. As shown in Fig. 6(a) and (c) for the impingement at low angle of $30^{\circ}$, the surface morphologies exhibit lots of long furrows and ridges, which are ploughed out by the impinged

Table 3

Surface hardness after impingement erosion of $2 \mathrm{~h}$ at various impinged angles for NiCrBSi sprayed coating and SUS304 stainless steel

\begin{tabular}{llllllll}
\hline Specimens & \multicolumn{6}{l}{ Hardness $(\mathrm{Hv})$} \\
\cline { 2 - 8 } & $\begin{array}{l}\text { Before } \\
\text { erosion }\end{array}$ & \multicolumn{6}{l}{ Impinged angles } \\
\cline { 3 - 8 } & $15^{\circ}$ & $30^{\circ}$ & $45^{\circ}$ & $60^{\circ}$ & $75^{\circ}$ & $90^{\circ}$ \\
\hline NiCrBSi coating & 756 & 769 & 772 & 779 & 773 & 780 & 779 \\
SUS304 & 264.3 & 323.5 & 348.0 & 422.9 & 428.5 & 470.0 & 481.0 \\
\hline
\end{tabular}


particles, regardless of the SUS304 stainless steel or NiCrBSi sprayed coating. Carefully examining Fig. 6(a) and (c), the impinged furrows and ridges of $\mathrm{NiCrBSi}$ sprayed coating seem to be shallower than those of SUS304 stainless steel. At a high impinged angle of $90^{\circ}$, the surface morphology of SUS304 stainless steel exhibits lots of overlapping and irregular concavities, as shown in Fig. 6(b). This is because the impact force of particles at high impinged angles is mostly used to induce plastic deformation for SUS304 stainless steel. The combined deformation of microforging and extrusion will produce indented concavities and protruding thin platelets. These protruding thin plates will then be partially impinged off by the subsequent impinged particles or attached onto the nearby surface, as the arrows indicate in Fig. 6(b). However, for the NiCrBSi sprayed coating with an extra-high hardness, less plastic deformation is induced during the impingement. Meanwhile, the micro-porosities existing within the sprayed coating are considered as the preferential sites for erosion damage. Hence, the overlapping concavities and protruding thin platelets are less obvious for the $\mathrm{NiCrBSi}$ sprayed coating. Instead, some concavities originating from the micro-porosities can be observed in Fig. 6(d).

Table 3 presents the surface hardness after an impingement erosion of $2 \mathrm{~h}$ at various impinged angles for both $\mathrm{NiCrBSi}$ sprayed coating and SUS304 stainless steel. The surface hardness of the impinged specimens has a similar value although the impinged speeds are different. In Table 3, the surface hardness of NiCrBSi sprayed coating is nearly unchanged after impingement erosion at various impinged angles. This feature is reasonable because the NiCrBSi sprayed coating has an extra-high hardness and toughness. There is no obvious work hardening for this specimen because less plastic deformation occurs during the impingement erosion. However, the surface hardness of SUS304 stainless steel is found to be significantly raised after the impingement erosion. This is due to work hardening induced by the high-speed slurry impingement. Meanwhile, the work-hardening effect is more obvious at higher impinged angles. This is because the normal compressive force impacting on the surface is higher at higher impinged angles and will induce greater and more extensive plastic deformation, and hence enhance the work hardening. Though local strains may be introduced during the cutting process at lower impinged angles, only slight plastic deformation occurs on the impinged surface and hence the work hardening is low.

\section{Conclusions}

The high-speed slurry erosion characteristics of $\mathrm{NiCrBSi}$ sprayed coating and SUS304 stainless steel are examined and result in the following conclusions.

1. The post-thermal-treated NiCrBSi coatings have an extrahigh hardness and small quantity of porosity. They can exhibit a much better slurry erosion resistance than the SUS304 stainless steel, especially at lower impinged angles and higher impinged speeds. A preliminary test has revealed that the NiCrBSi spray coating can increase significantly the using-life, 3-4 times, of needles and nozzles in hydraulic machinery.
2. The erosion rate for the $\mathrm{NiCrBSi}$ sprayed coating slightly increases with impinged angles. However, a maximum erosion rate appears at an impinged angle of $30^{\circ}$ for SUS304 stainless steel, especially at higher impinged speeds.

3. The surface morphologies exhibit lots of long furrows and ridges at a low impinged angle of $30^{\circ}$, regardless of the SUS304 stainless steel or NiCrBSi sprayed coating. At a high impinged angle of $90^{\circ}$, the SUS304 stainless steel exhibits an impinged surface with lots of overlapping and irregular concavities due to the deformation of microforging and extrusion. However, these features are less obvious for $\mathrm{NiCrBSi}$ sprayed coating, due to its extra-high hardness and the micro-porosities existing within the sprayed coating.

4. The hardness of SUS304 stainless steel increases significantly with increasing impinged angle during the high-speed slurry erosion. But, there is no obvious work hardening for the NiCrBSi sprayed coating due to its extra-high hardness and less plastic deformation, even at a high impinged angle of $90^{\circ}$.

\section{Acknowledgement}

The authors gratefully acknowledge Dr. Y.H. Shieh, Power Research Institute, Taiwan Power Company, Taiwan, for his kind assistance in the specimen preparation.

\section{References}

[1] H. Xu, X. Luo, Proceedings of the 19th IAHR Symposium on Hydraul. Ach. Cavitation, 1998, p. 544.

[2] S. Hattori, Turbomachinery 30 (10) (2002) 644.

[3] A.R. Nicoll, Thin Solid Films 95 (1982) 285.

[4] Qian Ming, L.C. Lim, Z.D. Chen, Surf. Coat. Technol. 106 (1998) 174.

[5] E. Fernandez, M. Cadenas, R. Gonzalez, C. Navas, R. Fernandez, J. Damborenea, Wear 259 (2005) 870.

[6] A. Conde, F. Zubiri, J. Damborenea, Mater. Sci. Eng., A Struct. Mater.: Prop. Microstruct. Process. 334 (1-2) (2002) 233.

[7] J. Rodriguez, A. Martin, R. Fernandez, J.E. Fernandez, Wear 255 (2003) 950.

[8] A.V. Levy, B. Wang, Wear Mater. (1987) 477.

[9] F. Otsubo, H. Era, K. Kishitake, J. Therm. Spray Technol. 9 (1) (2000) 107.

[10] L.C. Betancourt-Dougherty, R.W. Smith, Wear 217 (1998) 147.

[11] K. Sang, Y. Li, Wear 189 (1995) 20.

[12] J.P. Tu, M.S. Liu, Z.Y. Mao, Wear 209 (1997) 43.

[13] K. Sugiyama, S. Nakahama, S. Hattori, K. Nakano, Wear 258 (2005) 768.

[14] Y.H. Shieh, J.T. Wang, H.C. Shih, S.T. Wu, Surf. Coat. Technol. 58 (1993) 73

[15] J.M. Miguel, J.M. Guilemany, S. Vizcaino, Tribol. Int. 36 (2003) 182.

[16] ASTM G73-93, Liquid Impingement Erosion Testing, ASTM, 1993.

[17] ASTM G76-95, Conducting Erosion Tests by Solid Particle Impingement Using Gas Jets, ASTM, 1995.

[18] A.W. Ruff, L.K. Ives, Wear 35 (1975) 195.

[19] K. Haugen, O. Kvernvold, A. Ronald, R. Sandberg, Wear 186-187 (1995) 179.

[20] R.J.K. Wood, Mater. Des. 20 (1999) 179.

[21] R. Richardson, Wear 10 (1967) 291.

[22] S.S. Aptehar, Wear of Materials, ASME, New York, 1985, p. 677.

[23] I.M. Hutchings, R.E. Winter, J.E. Field, Proc. R. Soc. Lond., A 348 (1976) 379

[24] K.Z. Gahr, Microstructure and Wear of Material, Tribology Series, vol. 10, Elsevier Science Publishing Company, Inc., 1987.

[25] I. Finnie, D.H. McFadden, Wear 48 (1978) 181.

[26] I.M. Hutchings, Wear 70 (1981) 269.

[27] G. Sundararajan, P.G. Shewmon, Wear 84 (1983) 237.

[28] R. Bellman, A. Levy, Wear 70 (1981) 1.

[29] C.T. Morrison, R.O. Scattergood, Wear 111 (1986) 1. 